\title{
Micronutrient therapy and effective immune response: a promising approach for management of COVID-19
}

\author{
Fariba Lotfi ${ }^{1}$ Mostafa Akbarzadeh-Khiavi ${ }^{2,3} \cdot$ Ziba Lotfi $^{4} \cdot$ Leila Rahbarnia $^{1}\left(\mathbb{D} \cdot\right.$ Azam Safary $^{5}\left(\right.$ A Habib Zarredar $^{6}$. \\ Amir Baghbanzadeh ${ }^{4}$ Behrooz Naghili ${ }^{1} \cdot$ Behzad Baradaran ${ }^{4}$
}

Received: 10 April 2021 / Accepted: 16 June 2021 / Published online: 23 June 2021

○) Springer-Verlag GmbH Germany, part of Springer Nature 2021, corrected publication 2022

\begin{abstract}
The escalating prevalence of coronavirus disease 2019 (COVID-19) worldwide, with an increased rate of morbidity and mortality, highlights an urgent need to develop more effective therapeutic interventions. Despite the authorized treatment against COVID-19 by the European Union (EU), the safety and effectiveness of this therapeutic strategy for a wide variety of patients have remained a significant challenge. In this respect, micronutrients such as vitamins and minerals, as essential factors, can be considered for improving the function of the immune system and accelerating the treatment procedure. Dietary supplements can attenuate vascular and inflammatory manifestations related to infectious diseases in large part due to their anti-inflammatory and antioxidant properties. Recently, it has been revealed that poor nutritional status may be one of the notable risk factors in severe COVID-19 infections. In the current review, we focus on the micronutrient therapy of COVID-19 patients and provide a comprehensive insight into the essential vitamins/minerals and their role in controlling the severity of the COVID-19 infection. We also discuss the recent advancements, challenges, negative and positive outcomes in relevance to this approach.
\end{abstract}

Keywords COVID-19 $\cdot$ Immune response $\cdot$ Micronutrient therapy $\cdot$ Minerals $\cdot$ Vitamins

\section{Introduction}

Fariba Lotfi and Mostafa Akbarzadeh-Khiavi have an equal contribution as the joint first authors.

Leila Rahbarnia

le.rahbarnia@gmail.com

Azam Safary

safarya@tbzmed.ac.ir

1 Infectious and Tropical Diseases Research Center, Tabriz University of Medical Sciences, P.O. Box 5163639888, Tabriz, Iran

2 Liver and Gastrointestinal Diseases Research Center, Tabriz University of Medical Sciences, Tabriz, Iran

3 Research Center for Pharmaceutical Nanotechnology, Biomedicine Institute, Tabriz University of Medical Sciences, P.O. Box 5165665811, Tabriz, Iran

4 Immunology Research Center, Tabriz University of Medical Sciences, Tabriz, Iran

5 Connective Tissue Diseases Research Center, Tabriz University of Medical Sciences, Tabriz, Iran

6 Tuberculosis and Lung Diseases Research Center, Tabriz University of Medical Science, Tabriz, Iran
Currently, coronavirus disease 2019 (COVID-19) caused by severe acute respiratory syndrome coronavirus 2 (SARSCoV-2) has become a global problem [1-3]. This virus is known as the main cause of severe acute respiratory infections, pneumonia, kidney failure, or even death [4]. Despite, significant advances in the control of the wide variety of diseases such as cancers and infections [5-8], confronting the COVID-19 pandemic remains an outstanding challenge. Regarding the scientists' efforts, only a limited number of drugs such as Veklury (remdesivir) are now authorized in the European Union (EU) for COVID-19 patients from 12 years of age with pneumonia and requiring supplemental oxygen. Remdesivir is recommended as the first drug in the EU under a "conditional marketing authorization" mechanism that facilitates early access to medicines with less comprehensive data in an emergency condition such as the COVID-19 pandemic. However, the safety, effectiveness, and availability of this therapeutic strategy are under monitoring because impactful factors such as high cost and side effects may limit their applications for a wide variety of 
patients. Thus, there is an urgent need for developing supplementary agents and drugs to increase the treatment chance of COVID-19 patients.

Based on recent studies, poor nutritional status and suboptimal intakes can lead to inadequate immune responses, subsequently affect the severity of infections [9]. Micronutrients such as vitamins and minerals are involved in numerous stages of the immune response due to their anti-inflammatory and antioxidant properties, which can attenuate vascular and inflammatory manifestations related to COVID-19 [10]. Overall, vitamins A, B, C, D, E, and minerals are needed to preserve the structure and function of the first line of defense systems including the skin and mucus membranes. The cellmediated immune responses including the capacity of the stem cells for proliferation, differentiation, and movement depend on suitable levels of vitamins (e.g., D, A, C, E, B6, B12) and minerals (e.g., iron, zinc, folate, copper, magnesium, and selenium) [11]. Likewise, chemical responses and complement system activation such as the production of proinflammatory cytokines are dependent on adequate levels of certain vitamins especially vitamins $\mathrm{A}, \mathrm{C}, \mathrm{D}$, and minerals such as zinc, iron, and selenium. On the other hand, the relevance between the adaptive and innate immune system which is essential for inducing inflammatory responses can be regulated by sufficient amounts of vitamins and minerals including A, C, E, and B6, iron, zinc, and copper. Currently, it has been recommended that medical nutritional therapy can be utilized in hospitalized COVID-19 patients for improving the therapeutic response of the patients and reducing the duration of admissions [12]. In the current review, we focus on the micronutrition therapy of COVID19 and provide a comprehensive insight into the essential vitamins/minerals and their role in controlling the COVID19 infection. We also discuss the recent advancements, challenges, negative and positive outcomes in relevance to the micronutrition therapy in COVID-19.

\section{COVID-19 characteristics}

\section{Clinical features of COVID-19}

Generally, coronaviruses (CoV) are categorized into four main genogroups including alpha $(\alpha)$, beta $(\beta)$, gamma $(\gamma)$, and delta $(\delta)$ [13]. The mammalians are known as the main host for $\alpha$ - and $\beta-\mathrm{CoV}$, whereas birds are known as the main host for $\gamma$ - and $\delta$-CoV [14]. Based on reports, six CoVs comprising $\alpha$-CoVs (HCoV-229E and HCoV-NL63), and $\beta$-CoVs (HCoV-HKU1 and HCoV-OC43) are human-susceptible viruses cause of mild respiratory symptoms such as common cold, while two $\beta$-CoVs, (SARS-CoV and MERS$\mathrm{CoV}$ ) lead to severe respiratory infections [15-17].
Most clinical manifestations have been reported in similar studies $[18,19]$. Based on a systematic review, about 26 different clinical manifestations have been observed in COVID-19 patients, of which six symptoms are more prevalent, including cough, fever, malaise, dyspnea, sputum/secretion, and fatigue [20]. The most common clinical manifestations at the onset of illness are fever (83-98\%), dry cough (76-82\%), shortness of breath (31-55\%), fatigue (38\%), dyspnea (18.7\%), and myalgia (14.9\%) [21]. It is noteworthy that lung involvement is the most critical manifestation of this disease [17], which is presented as dyspnea, oxygen saturation $(\mathrm{SpO} 2)<90 \%, \mathrm{PaO}_{2} / \mathrm{FiO}_{2}$ ratio $\leq 300$, respiratory rate of 30 or more breaths per minute, and lung involvement up to $50 \%$ during $24-48 \mathrm{~h}$ [21]. The most frequent digestive symptoms are anorexia, vomiting, and diarrhea in COVID19 patients [22], while some of the patients are even asymptomatic [21, 23, 24]. Moreover, there are significant differences in hematological and clinical variables between the non-survivors and survivors of COVID-19 patients. Based on recent studies, lymphocyte count was notably lower, while neutrophil and white blood cell count were remarkably higher in the deceased patients [25, 26]. On the other hand, the values of procalcitonin, $\mathrm{C}$-reactive protein ferritin, and D-dimer were significantly higher [25].

It is noteworthy that almost $20 \%$ of COVID-19 patients are hospitalized due to severe respiratory manifestations [27-29] with a fatality rate of $20-30 \%$ in hospitalized adult patients $[26,30]$. Findings from a systematic review and meta-analysis of 212 studies on 281,461 COVID-19 patients have indicated a more tendency of males for severe infections than females since $51.8 \%$ of patients were male, which $22.9 \%$ of them showed severe symptoms with a mortality rate of 5.6\%. Overall, immunosuppression, diabetes, and malignancy were considerably related to severe COVID-19, whereas diabetes, hypertension, male gender, and older age were related to a higher mortality rate. Respiratory and gastrointestinal symptoms were also related to severe COVID19, while end-organ damage and pneumonia were related to mortality. Regarding the severe features of COVID-19, patients with comorbidities should be monitored closely, and critical care must be taken to prevent and treat, especially in patients with malignancy, diabetes, and immunosuppression [31].

\section{Structural properties of SARS-CoV-2}

The SARS-CoV-2, as a positive sense ribonucleic acid virus, belongs to the Coronaviridae family [21, 32]. The main structural proteins in coronaviruses are nucleocapsid polymer $(\mathrm{N})$, spike polymer $(\mathrm{S})$, protein receptor $(\mathrm{E})$, and membrane protein (M) [33-36]. The $\mathrm{S}$ glycoprotein (from 1100 to 1600 residues), as a class I viral fusion protein of SARS-CoV-2, plays a crucial role in the virus entry into the 
host cells [21, 37]. The $\mathrm{S}$ protein is comprised of two subunits including $\mathrm{S} 1$ and $\mathrm{S} 2$, which the $\mathrm{S} 1$ subunit is responsible for the virus entry through interaction between its receptor binding site and angiotensin-converting enzyme 2 (ACE2) cellular receptor for cellular attachment [21]. The ACE2 is known as the entry receptor for coronaviruses and generally is expressed on the surface of the lung, intestine, kidney, and blood-vessel epithelial cells [22]. As shown in Fig. 1, at the beginning step, the $\mathrm{S}$ protein is activated through cleavage at the $\mathrm{S} 1 / \mathrm{S} 2$ and $\mathrm{S} 2$ sites by a transmembrane serine protease 2 (TMPRSS2), which facilitates the virus fusion into the cellular membrane $[38,39]$. Subsequently, the viral RNA is released into the cytoplasm and converted into polyproteins and structural proteins [40]. Therefore, blocking the binding of S protein to ACE2 may be considered as a promising strategy for the treatment of SARS-CoV infection [41]. However, the polymorphisms of the ACE2 gene play important role in binding viral $S$ protein to the cell membrane. The high expression of ACE2 can lead to the rise of COVID-19 infection. Nevertheless, ACE2-stimulating drugs could increase the risk of severe COVID-19 viral infection [22]. On the other hand, ACE2 can hydrolyze the active bradykinin metabolite DABK (desArg9-bradykinin), hence, the reduction of ACE2 expression leads to DABK inactivation. As a result, the signaling of the bradykinin $\mathrm{B} 1$ receptor (BKB1R) improves the recruitment of leukocytes into the lung. Based on reported results, blocking the bradykinin system may be considered as a promising therapeutic technique to resolve acute respiratory distress syndrome (ARDS) caused by COVID-19 [42, 43]. It is noteworthy that $\mathrm{S}$ protein is considered as the main target in the COVID-19 vaccine due to produce a high titer of neutralizing antibodies in most patients [44, 45]. To date, several vaccines based on recombinant vector expressing the recombinant $\mathrm{S}$ protein, DNA, and mRNA vaccine technology have been authorized or are under clinical evaluation in different countries [46, 47]. In this respect, WHO Emergency Use Listing (EUL) has reported the administration of at least thirteen different vaccines (e.g., Pfizer/BioNtech, AstraZeneca/AZD1222, Janssen/Ad26.COV 2.S, and Moderna). Besides, recent studies have focused on developing effective therapeutic agents against COVID -19, such as antiviral drugs and antibody therapy [48, 49]; however, the pivotal role of consuming nutrients, vitamins, and minerals cannot be ignored [50].

\section{Vitamins and minerals in the immune function}

There is a bidirectional association between malnutrition and infection. Several types of micronutrients including vitamin A, D, C, E, B6, B12, folate, zinc, iron, copper, and selenium are involved in different stages of the immune responses. For instance, vitamin A plays important role in the maintenance of the structure/function of skin and mucosal cells, regulation of the interleukin-2 (IL-2) and TNF- $\alpha$ level, and activation of macrophage antimicrobial function [51, 52]. The composition of intestinal microbiota (e.g., the balance between commensal and pathogenic microorganisms) is affected by vitamins D [53, 54], A, B6, and B12, and folate [55-58]. In this regard, gut microbes can affect the host immune system through a balance between innate and adaptive immune homeostasis [59]. Gastrointestinal tract microbiota modulates the migration of neutrophils and their

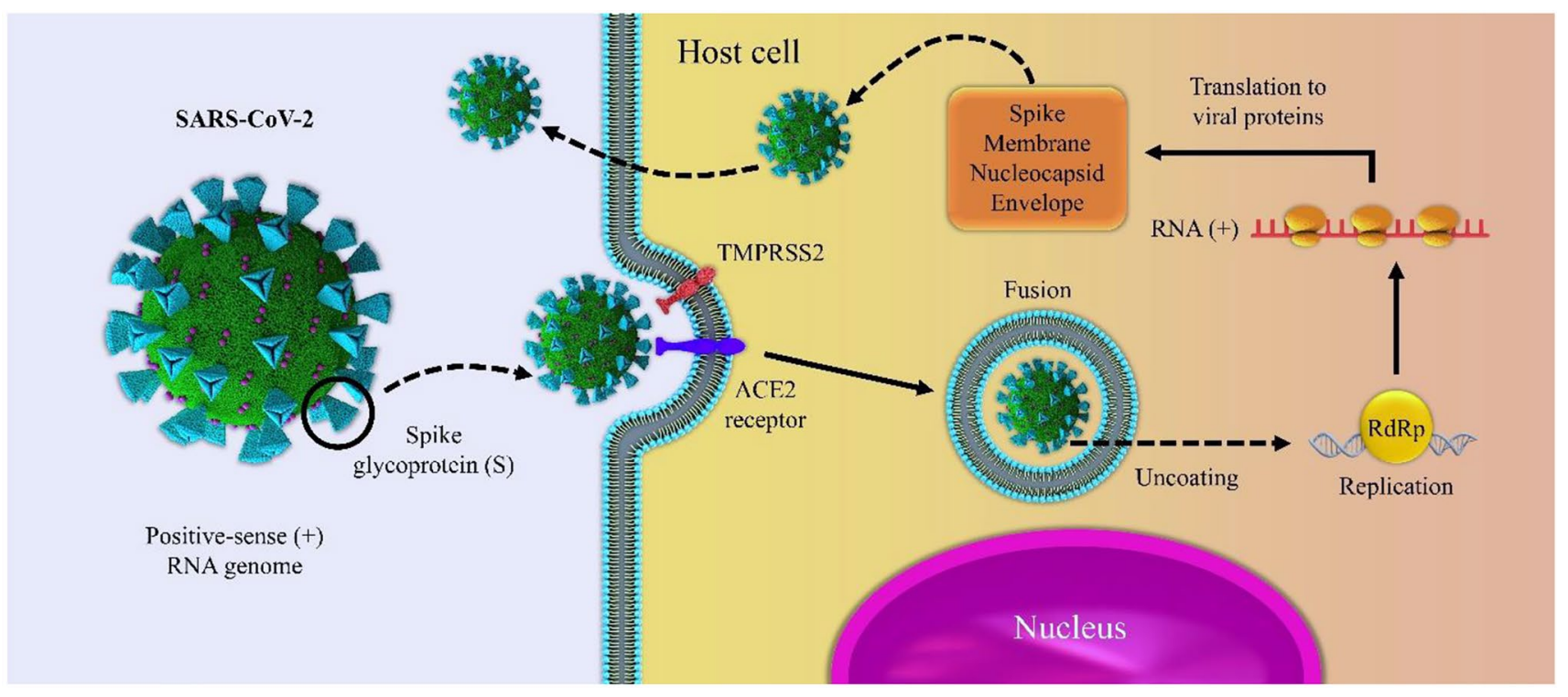

Fig. 1 Schematic presentation of the infection and replication model of SARS-CoV-2 in the host cells 
function [60]. On the other hand, it can differentiate T cells into regulatory $\mathrm{T}$ cells and helper cells (Th1, Th2, and Th17) [61].

Besides, vitamin D can reduce the expression of proinflammatory cytokines, increase the production of antiinflammatory cytokines through macrophages, suppress the p38 activation, and upregulate the MAPK phosphatase-1 (MKP-1) activation [42, 62-64]. The expression of prostaglandin E2 with immunosuppressive effects is regulated by vitamin E level $[52,65]$. According to the previous studies, a high level of pyridoxal 5'-phosphate (PLP), an active form of vitamin B6, results in a low level of chronic inflammation responses [66]. Additionally to the vitamins, minerals such as iron and zinc are essential for the differentiation, growth of epithelial tissues [10], and act as anti-inflammatory agents [52]. In a recent study, $91.7 \%$ of COVID-19 patients have indicated one or more nutrients deficiencies. In another study performed on 50 COVID-19 patients, vitamin D and selenium deficiency were reported in 76 and $42 \%$ of patients, respectively [67]. It has been demonstrated that each of the vitamins alone or in combination with other vitamins and minerals can be effective in the control of infectious diseases and their progress [68]. Each of the vitamins or combination of them is required for inducing a distinct stage of the immune response. For instance, vitamins $\mathrm{A}, \mathrm{D}, \mathrm{E}$, and $\mathrm{C}$ have a notable role in the modification of the immune system $[69,70]$. The following contexts briefly introduce the most important vitamins and minerals related to the COVID-19 treatment and control.

\section{Vitamin A}

There are three active forms of vitamin A including retinoic acid, retinol, and retinal acid. Vitamin A is a fat-soluble vitamin that plays a pivotal role in activating the immune system, including inherent immunity, humoral immunity, and specific immunity mediated by cells [71]. The function of vitamin A is related to the rise of T-cell proliferation, signaling, and function, and stimulation of IL-2 secretion $[72,73]$. It has been reported that deficiency of vitamin A in mice can be associated with severe defects in T-helper activity [74]. Besides, retinoids act as effectors of the T-cellmediated adaptive and innate immune responses by stimulating antigen-presenting dendritic cells (DCs), natural killer (NK) cells, and innate lymphoid cells (ILCs) [75, 76].

Due to the different functions of vitamin A such as immunomodulatory and antimicrobial activity, it can be considered as an important factor in the fight against viral infections such as COVID-19 [77]. It has been demonstrated that retinoic acid is involved in modulating the pathogenesis of acute respiratory distress syndrome (ARDS), the production of IL1- $\beta$ and IL- 1 receptor antagonists by alveolar macrophages, and the subsequent pulmonary infiltration of neutrophils [78]. Moreover, retinoic acid in combination with simvastatin has indicated notable effects in pulmonary restoration and remodeling [79].

Vitamin A is also known as an anti-infective agent. The related studies indicate that vitamin A therapy can reduce measles virus $(\mathrm{MeV})$ replication through inhibiting type I interferon (IFN) signaling [80]. Besides, some studies have confirmed the direct inhibitory effects of retinoids on the replication of some viruses, including hepatitis B virus (HBV), cytomegalovirus (CMV), influenza A virus, measles virus $(\mathrm{MeV})$, and norovirus [16, 58, 81, 82]. These findings highlight the application of vitamin A as a promising therapeutic candidate alone or in combination with other antiviral agents against COVID-19 [15, 83]. Based on a systematic review regarding the relationship between vitamin A status and severity of respiratory tract infections, vitamin A deficiency has been confirmed in 12-46\% of children with respiratory tract infections $[19,23,84]$.

Moreover, the effect of riboflavin and UV light on plasma and whole blood inoculated with SARS-CoV-2 indicated a significant reduction in the SARS-CoV-2 titer [85]. A clinical study regarding the effect of vitamin A on COVID -19 patients has been presented in Table1 (NCT04900415). There are some pieces of evidence that SARS-CoV and MERS-CoV prevent IFN-I-mediated antiviral responses and subsequently can interfere with treatment efficacy [86-88]. In this regard, it has been suggested that retinoids can potentiate the function of IFN-I. These findings highlight the potential role of retinoids in combination with IFN-I against COVID-19.

\section{B-complex vitamins}

B-complex vitamins are a group of water-soluble vitamins comprised of eight members including B1 (thiamin), B2 (riboflavin), B3 (niacin), B6 (pyridoxine), B12, folate (folic acid), biotin, and pantothenic acid. Vitamin B1 has a key role in muscle contraction and transmission of nerve signals through releasing energy from foods [21]. It has been shown that thiamin deficiency can potentially lead to more severe symptoms in COVID-19 patients through increasing inflammation and aberrant antibody responses. Besides, a sufficient level of thiamin, as a carbonic anhydrase isoenzyme inhibitor [89] can prevent hypoxia in patients and decrease the hospitalization rate [90].

Vitamin B2 (riboflavin) is involved in the energy metabolism of the body cells [91]. In a study conducted by Keil et al., vitamin B2 coupled with UV light resulted in a reduction of MERS-CoV's titer in human plasma products. However, it has a leading cause in the incidence of severe hypoxemia [92]. Vitamin B3 or niacin has a potent antiinflammatory impact through the reduction of neutrophil accumulation in the lungs during ventilator-induced lung 
Table 1 Current clinical trials related to vitamin therapy in COVID-19 patients

\begin{tabular}{|c|c|c|c|c|c|}
\hline Vitamins & NCT number & Study title & Phase & Age & Status $^{*}$ \\
\hline Vitamin A & NCT04900415 & $\begin{array}{l}\text { Olfactory and Neurosensory Rehabilitation in COVID- } \\
\text { 19-related Olfactory Dysfunction }\end{array}$ & 2 & 18 years and older & Recruiting \\
\hline \multirow[t]{17}{*}{ Vitamin D } & NCT04344041 & $\begin{array}{l}\text { COVID-19 and vitamin D supplementation: a multicenter } \\
\text { randomized controlled trial of high dose versus standard- } \\
\text { dose vitamin d3 in high-risk COVID-19 patients } \\
\text { (CoVitTrial) }\end{array}$ & 3 & 70 years and older & Completed \\
\hline & NCT04709744 & $\begin{array}{l}\text { Impact of vitamin D level and supplement on SLE patients } \\
\text { during COVID-19 pandemic }\end{array}$ & NA & $18-80$ years & Completed \\
\hline & NCT04535791 & $\begin{array}{l}\text { Efficacy of vitamin D supplementation to prevent the risk } \\
\text { of acquiring COVID-19 in healthcare workers (COVID- } \\
\text { 19) }\end{array}$ & 3 & 18- 70 years & Recruiting \\
\hline & NCT04386850 & Oral 25-hydroxyvitamin D3 and COVID-19 & $2 / 3$ & $18-75$ years & Recruiting \\
\hline & NCT04411446 & $\begin{array}{l}\text { Cholecalciferol to improve the outcomes of COVID-19 } \\
\text { patients }\end{array}$ & 4 & 18 years and older & Recruiting \\
\hline & NCT04385940 & Vitamin D and COVID-19 management & 3 & 17 years and older & Recruiting \\
\hline & NCT04482673 & $\begin{array}{l}\text { Vitamin D supplementation in the prevention and mitiga- } \\
\text { tion of COVID-19 infection }\end{array}$ & 4 & 50 years and older & Recruiting \\
\hline & NCT04883203 & $\begin{array}{l}\text { The effect of vitamin D supplementation on COVID-19 } \\
\text { recovery (COVID-VITD) }\end{array}$ & 3 & $18-70$ years & Completed \\
\hline & NCT04525820 & $\begin{array}{l}\text { High dose vitamin-d substitution in patients with COVID- } \\
\text { 19: a randomized controlled, multi-center study }\end{array}$ & NA & 18 years and older & Recruiting \\
\hline & NCT04552951 & $\begin{array}{l}\text { Effect of vitamin D on morbidity and mortality of the } \\
\text { COVID-19 (COVID-VIT-D) }\end{array}$ & 4 & Child, adult, older adult & Recruiting \\
\hline & NCT04411446 & $\begin{array}{l}\text { Cholecalciferol to improve the outcomes of COVID-19 } \\
\text { patients (CARED) }\end{array}$ & 4 & 18 years and older & Recruiting \\
\hline & NCT04636086 & $\begin{array}{l}\text { Effect of vitamin D on hospitalized adults with COVID-19 } \\
\text { infection }\end{array}$ & 4 & 18 years and older & Recruiting \\
\hline & NCT04733625 & $\begin{array}{l}\text { The effect of vitamin D therapy on morbidity and mortal- } \\
\text { ity in patients with SARS-CoV } 2 \text { infection }\end{array}$ & NA & 18 years and older & Completed \\
\hline & NCT04344041 & $\begin{array}{l}\text { Covid-19 and vitamin D supplementation: a multicenter } \\
\text { randomized controlled trial of high dose versus standard- } \\
\text { dose vitamin d3 in high-risk COVID-19 patients } \\
\text { (CoVitTrial) }\end{array}$ & 3 & 65 years and older & Completed \\
\hline & NCT04459247 & $\begin{array}{l}\text { Short term, high dose vitamin d supplementation for } \\
\text { COVID-19 (SHADE) }\end{array}$ & NA & 18 years and older & Active, not recruiting \\
\hline & NCT04621058 & $\begin{array}{l}\text { Efficacy of vitamin D treatment in mortality reduction due } \\
\text { to COVID-19 }\end{array}$ & 3 & Child, adult, older adult & Recruiting \\
\hline & NCT04502667 & $\begin{array}{l}\text { Efficacy of vitamin D treatment in pediatric patients hospi- } \\
\text { talized by COVID-19 }\end{array}$ & 3 & 1 month to 17 years & Recruiting \\
\hline \multirow[t]{6}{*}{ Vitamin C } & NCT04401150 & Lessening organ dysfunction with vitamin C-COVID-19 & 3 & 18 years and older & Recruiting \\
\hline & NCT04357782 & $\begin{array}{l}\text { Administration of intravenous vitamin c in novel corona- } \\
\text { virus infection (COVID-19) and decreased oxygenation } \\
(\mathrm{AVoCaDO})\end{array}$ & $1 / 2$ & $18-99$ years & Completed \\
\hline & NCT04344184 & $\begin{array}{l}\text { Safety study of early infusion of vitamin c for treatment } \\
\text { of novel coronavirus acute lung injury (SAFE EVICT } \\
\text { CORONA-ALI) }\end{array}$ & 2 & 18 years and older & Recruiting \\
\hline & NCT04682574 & $\begin{array}{l}\text { Role of mega dose of vitamin c in critical COVID-19 } \\
\text { patients }\end{array}$ & NA & Child, adult, older adult & Recruiting \\
\hline & NCT04363216 & $\begin{array}{l}\text { Pharmacologic ascorbic acid as an activator of lymphocyte } \\
\text { signaling for COVID-19 treatment }\end{array}$ & 2 & 18 years and older & Not yet recruiting \\
\hline & NCT04710329 & $\begin{array}{l}\text { High-dose vitamin c treatment in critically ill COVID-19 } \\
\text { patients }\end{array}$ & NA & $18-99$ years & Completed \\
\hline
\end{tabular}

*Please refer to http://clinicaltrials.gov for more details. 
injury [34]. It has been indicated that niacin, as a building block of NAD and NADP, could potentially decrease the production of pro-inflammatory cytokines such as IL-1 $\beta$, IL-6, and TNF- $\alpha$, which may be beneficial in controlling cytokine storm in COVID-19 patients [93, 94]. On the other hand, deficiency of cobalamin, or B12 can inhibit the immune system's ability to produce antibodies to viral infections. Severe deficiency even causes hyperhomocysteinemia, in which fatal blood clots are formed in the brain, lungs, and lower leg. Unfortunately, this deficiency has been overlooked regarding the examination of the cause of death in COVID-19 patients. Most animal products, such as eggs, milk, fish, and meat are containing vitamin B12. Besides, nutritional yeasts also pack vitamin B12 and are useful for vegans with a high risk of B12 deficiency. Different types of vitamin $B$ play a fundamental role in the induction of desirable immune responses, energy metabolism, improvement of respiratory function, and reduction of pro-inflammatory cytokine titer. Thus, they can be recommended as promising therapeutic candidates against COVID-19 [21, 95, 96]. Figure 2 shows the role of different types of vitamin B in SARS-CoV-2 binding, replication, and invasion. However, there are some limitations in the treatment of patients with B vitamins [97]. While B-complex intake seems safe, but high doses of B3 or B6 may be led to serious side effects.
A high dose of B6 vitamin can cause nerve damage, light sensitivity, and painful skin lesions [88]. Moreover, a high dose of B3 vitamin (niacin) may lead to high blood sugar levels, vomiting, skin flushing, and even liver damage [98].

\section{Vitamin C}

Vitamin $\mathrm{C}$ or ascorbic acid as an essential micronutrient has pleiotropic functions in the body due to its electron-donating capacity. It is known as a cofactor for a group of enzymes that are involved in biosynthetic and gene regulatory procedures. Vitamin C plays an important role in cell-mediated immunity related to the adaptive and innate immune systems [65]. Besides, vitamin $\mathrm{C}$ as an antioxidant agent can protect from oxidative stress-induced cellular damages through the elimination of reactive oxygen species (ROS), prevention of lipid peroxidation, and protein alkylation [99].

The main role of vitamin $\mathrm{C}$ in infectious diseases is related to its function in the (i) stimulation of the neutrophil migration into the site of infection, (ii) enhancement of the phagocytosis and oxidant production, and (iii) elimination of microbial germs [100]. Vitamin C through increasing neutrophil apoptosis and macrophage clearance, decreasing neutrophil necrosis can protect from extreme host tissue damages [65].
Fig. 2 The role of different types of vitamin B in COVID19 binding, replication, and invasion. Data were adapted with permission from a work published by Shakoor et al. [90]

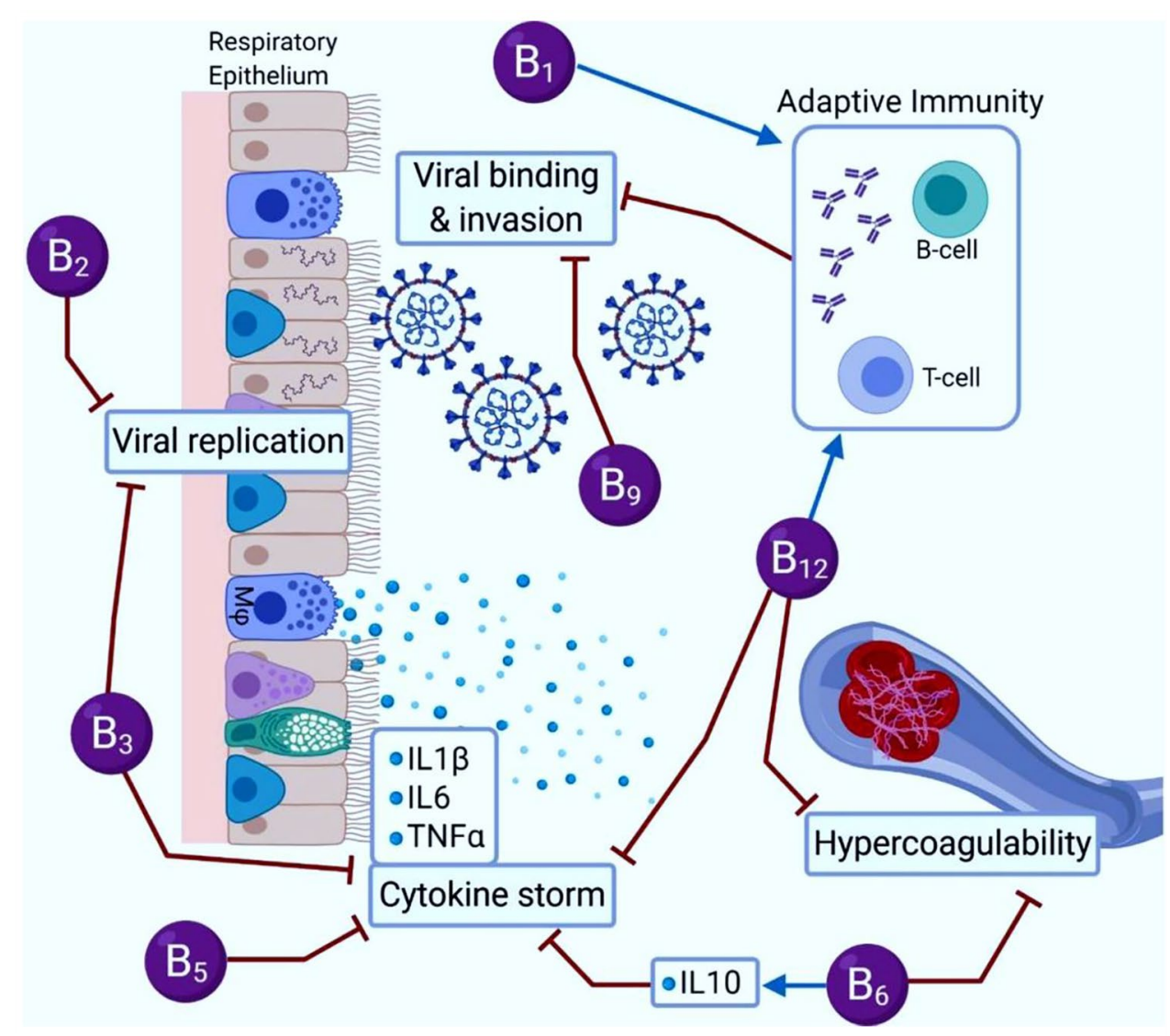


Recently, promising results have been obtained regarding the intravenous (IV) administration of vitamin $\mathrm{C}$ against COVID-19. At present, IV injection of vitamin $\mathrm{C}$ is used in Shanghai for the treatment of COVID-19 patients [67]. It has been suggested that vitamin $\mathrm{C}$ is involved in inducing a strong immune response and reducing the cytokines storm during COVID-19 infection. The reduction of the cytokines storm in the late stages of the COVID-19 considers as the most important function of vitamin C [67].

It has also been documented that the high-dose administration of vitamin $\mathrm{C}$ for patients with sepsis and acute respiratory distress syndrome does not change notably inflammation markers and improves organ dysfunction scores [23]. While early IV administration of vitamin $\mathrm{C}$ in combination with corticosteroids/thiamine can significantly prevent progressive organ malfunction and reduce the rate of mortality in patients with severe sepsis and septic shock [101]. However, there are contradictory results in this respect, for instance, in a cohort study on 94 patients with severe sepsis and septic shock, a triple therapy including hydrocortisone, vitamin $\mathrm{C}$, and thiamine was used but there were no favorable results related to hospital mortality, duration of hospitalization, intensive care unit (ICU) mortality, ICU length of stay, and time to vasopressor independence [102].

While vitamin $\mathrm{C}$ has low toxicity, it leads to gastrointestinal complications including diarrhea, abdominal pain, and/ or nausea in a dose up to $2 \mathrm{~g}$ per day [103, 104]. Since additional values of vitamin $\mathrm{C}$ can excrete in the urine, it may be the cause of renal stones [104]. Moreover, in patients with glucose-6-phosphate dehydrogenase (G6PD) deficiency, vitamin $C$ leads to hemolytic anemia disease [105]. Nevertheless, vitamin $\mathrm{C}$ concurrent with other antiviral agents or alone is currently considered as a promising therapeutic candidate against COVID-19 infection. Recently, several clinical studies have been conducted regarding the therapeutic effects of vitamin C on COVID-19 patients (Table 1).

\section{Vitamin D}

The circumstantial and experimental evidence indicates that vitamin D plays an imperative role in immunomodulatory, antioxidant activity, and antiviral responses [106]. Modulation of the innate and adaptive immune system through vitamin $\mathrm{D}$ is related to the regulation of $\mathrm{T}$ cell function, stimulation of Toll-like receptors (TLRs), and the generation of pro-inflammatory cytokines [107, 108]. It has been suggested that vitamin D can significantly minimize the pro-inflammatory production via the (i) selective form of inhibition of inflammatory cytokines, (ii) reducing leukocyte infiltration into the site of inflammatory, (iii) interaction with monocytes, macrophages, neutrophils, and mast cells [109-111], (iv) increasing the memory and regulatory
T cells (Treg), (v) reducing the neutrophil/lymphocyte ratio, and (vi) influencing the functional state of T cells [112-114].

The role of vitamin D in reducing the risk of respiratory tract infections is related to the expression of vitamin $\mathrm{D}$ receptors (VDRs), the generation of antimicrobial peptides in the human airway epithelium, and respiratory homeostasis $[107,115]$. The VDRs are extensively distributed in respiratory epithelial cells and immune cells (e.g., B cell, T cell, macrophages, and monocytes). The 25 -hydroxyvitamin $\mathrm{D}$ (25OHD), the major circulating form of vitamin D, can be converted to the active form $(1,25$-dihydroxy vitamin $\mathrm{D})$ in the bronchial epithelium and immune cells [116]. It has been demonstrated that vitamin D blocks NF- $\mathrm{kB}$ p65 activation via up-regulation of $\mathrm{I} \kappa \mathrm{B} \alpha(\mathrm{NF}-\kappa \mathrm{B}$ transcription factor inhibitory protein) [117]. Besides, vitamin $\mathrm{D}$ can reduce the expression levels of pro-inflammatory type 1 cytokines (e.g., IL-12, IL-16, IL-8, TNF- $\alpha$, IFN- $\gamma$ ), while increasing the expression of type 2 cytokines (e.g., IL-4, IL-5, IL-10), and Treg cells [118]. The immunomodulatory effects of vitamin D on multiple immune cell lineages have been shown in Fig. 3.

Vitamin D enhances the levels of nuclear factor erythroid 2-related factor 2 (NRF2), as a regulatory factor for the expression of antioxidants, and modulates mitochondrial activities. In addition, it can prevent lipid peroxidation, oxidative stress-related protein oxidation, and DNA damage [119]. Based on recent studies, the high susceptibility to acute respiratory infections caused by COVID-19 is associated with a notable deficiency of vitamin D [120]. It has been shown that vitamin $\mathrm{D}$ supplementation can significantly potentiate the innate immune responses to respiratory viral infections caused by influenza A and B, parainfluenza 1 and 2, respiratory syncytial virus (RSV), and chronic hepatitis C $[115,121]$.

Vitamin D through activation of TLRs or enhancement of cathelicidins and $\beta$-defensins levels can induce the innate immune system, as well as modulate $\mathrm{T}$ cells function and adaptive immune system through the reduction of immunoglobulin secretion by plasma cells and production of proinflammatory cytokines [107]. The studies highlight the preventive role of vitamin D supplementation in respiratory tract infections, autoimmune diseases, and pulmonary fibrosis [107].

There are some reports that this vitamin could suppress virus-induced inflammation and lead to antiviral activity. This function of vitamin D could inhibit the cytokine storms in COVID-19 patients. Based on the results of a randomized controlled trial (RCT), administration of a high-dose vitamin D (100,000 IU/per month) can reduce the incidence of acute respiratory infections in comparison to the standard dose (12,000 IU/month), especially in older long-term care residents [122, 123]. However, there is not enough evidence about the direct effect of vitamin D in viral replication and 


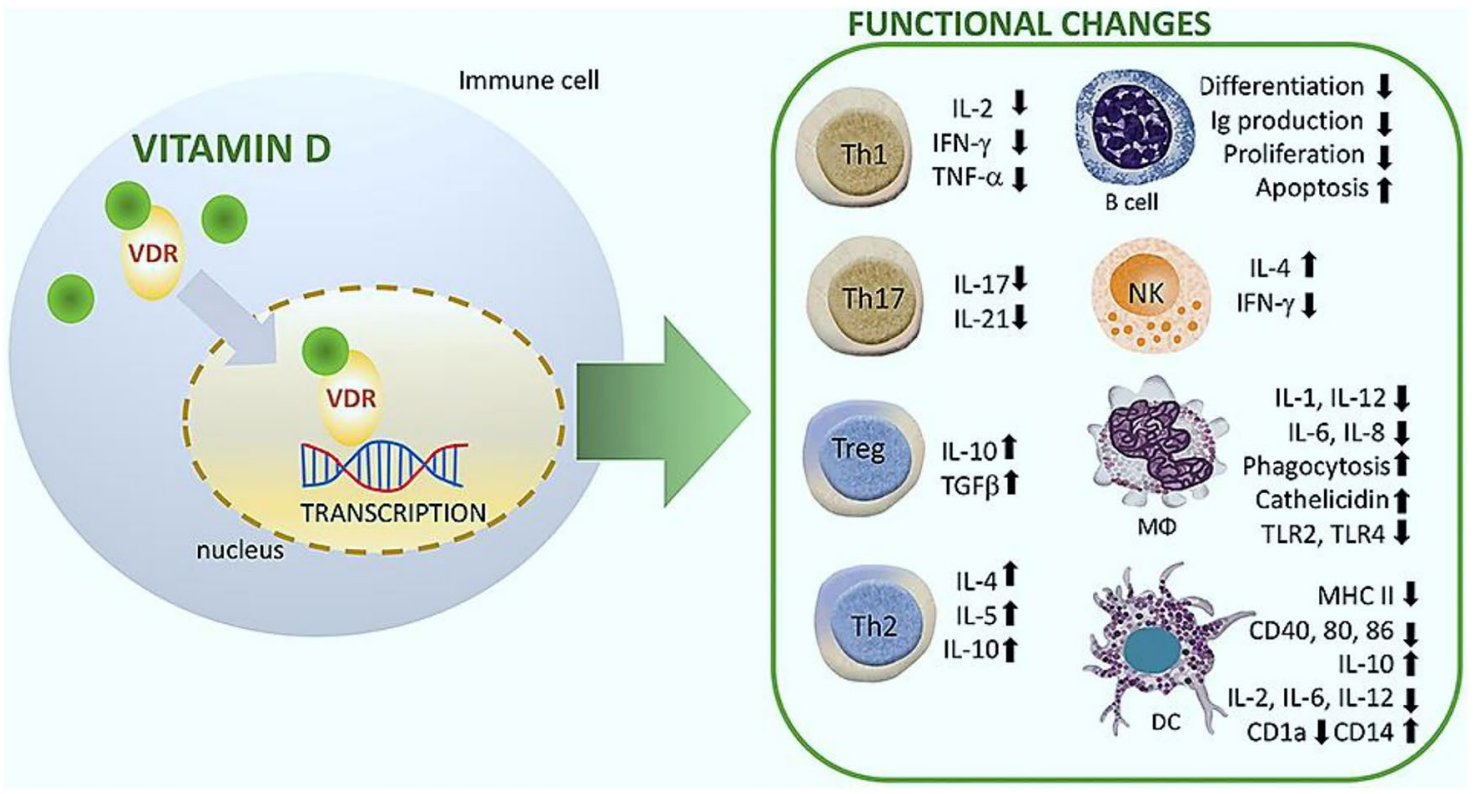

Fig. 3 Immunomodulatory effects of vitamin $\mathrm{D}(1,25(\mathrm{OH}) 2 \mathrm{D} 3)$ on multiple immune cell lineages. $N K$ natural killer; $D C$ dendritic cell; $R$ receptor; $V D R$ vitamin D Receptor; $M \Phi$ macrophage. Data were adapted with permission from a work published by Cyprian et al. [165]

load in COVID-19 patients. Based on recent findings, the level of vitamin D can influence serological response to influenza vaccine via improving the activity of CD8 $+\mathrm{T}$ cells. Since there is a relation between the dysfunction of $\mathrm{T}$ cells and the severity of COVID-19, vitamin D may improve the functionality of $\mathrm{CD} 8+\mathrm{T}$ cell response against coronavirus [124, 125].

Moreover, vitamin D through interaction with the reninangiotensin system (RAS) can promote the expression of ACE2. In the RAS the ACE cleaves angiotensin I (Ang I) into angiotensin II (Ang II). The binding of Ang II into type 1 receptor can lead to inflammation, lung injury, and leaky vessels. The function of ACE2 can be resulted in forming of Ang-(1-7) directly from the cleavage of Ang II. The endogenous ratio of Ang II/Ang-(1-7) is regulated by the balance between the level of ACE and ACE2 enzymes. In this pathway, vitamin D may interfere with RAS activity through the inhibition of renin and preventing Ang I production [126, 127]. The ACE2 exopeptidase is expressed in human airway epithelial cells, lung parenchyma, and especially in the epithelial lining of the oral cavity, converts Ang I to the nonapeptide Ang provides a suitable portal for SARS-CoV-2 virus entry [17, 128]. The stages of COVID-19 infection including (i) virus exposure and virus entry, (ii) virus replication, (iii) immune response against viral infection, and (iv) uncontrolled immune response. The supplementation of vitamin $\mathrm{D}$ in each stage of COVID-19 infection may possess potential advantages and some disadvantages. Currently, several clinical trials have been conducted regarding the treatment of COVID
-19 patients with vitamin D (Table 1), however, it has not been approved as an effective therapeutic agent against COVID-19, and further studies are warranted to confirm these findings.

\section{Vitamin E}

The fat-soluble vitamin $\mathrm{E}$ is known as one of the main components of antioxidant defense. Based on epidemiological researches, vitamin E deficiency is an effective factor in viral pathogenicity and immune responses. It is worthy to note that vitamin $\mathrm{E}$ through enhancement of the T cell numbers, IL-2 secretion, mitogenic lymphocyte responses, and NK cell activity can reduce the risk of infection. Based on reported results, vitamin E supplementation can significantly increase resistance to respiratory infections [90,129, 130].

Natural vitamin E is comprised of four tocopherols including alpha, beta, gamma, and delta-tocopherol. Among them, alpha-tocopherol is the only used form in the human body, which is needed to treat vitamin E deficiency. Nevertheless, mixed tocopherols are more effective than $\alpha$-tocopherol alone due to the range of receptors for these nutrients [131]. Despite the notable role of vitamin $\mathrm{E}$ in the immune system, there is inadequate information regarding the influence of vitamin $\mathrm{E}$ in COVID-19 patients, however, patients are encouraged to the adequate dietary ingestion of vitamin E [130]. 


\section{Selenium}

Selenium is an antioxidant that can reduce the oxidative stress induced by a viral infection. It also acts as an antiinflammatory agent and is crucial for a desirable immune response. It has been demonstrated that the low values of selenium are related to an increased risk of mortality and cognitive decline. However, it indicates antiviral effects in a suitable dose and harmful side effects in a high dose [21]. According to previous studies, selenium supplementation has shown a notable role in the control of viral infections [132, 133], such as HIV-1 [134, 135], liver cancer caused by hepatitis B, and epidemic hemorrhagic fever $[132,136]$. Furthermore, selenium through immunomodulation is effective in the evolution of a variety of viruses [137, 138]. It may alter the viral genome via oxidative stress from a benign or mildly pathogenic to a highly virulent virus in the host [139]. Selenium deficiency has commonly resulted in the weakness of the host immune system. So that, selenium supplementation in combination with a group of enzymes and vitamin $\mathrm{E}$ can limit the formation of free radicals and prevent oxidative damage to cells and tissues. Consequently, the supplementation of selenium could be considered as an effective mineral for the management of COVID-19 infection.

In a study performed on serum samples from COVID-19 patients, the selenium status was significantly higher in surviving than non-surviving patients [140]. Furthermore, in a similar study conducted in China, a linear association was observed between regional selenium status and the cure rate of COVID-19 patients [21, 23, 27, 32, 141-147]. There are a few studies regarding selenium therapy of COVID-19 due to variation in regional selenium status and the narrow range between toxicity and therapy essential dose (Table 2) [21].

\section{Zinc}

Currently, it has been revealed that zinc minerals can potentiate the immunity system against virus infections through (i) inducing IFN- $\gamma$ and IFN- $\alpha$ production, (ii) reducing mononuclear cells and TNF, and (iii) inhibiting the virus entry via increasing the stability of the cell membrane [148-150]. Zinc supplementation is also capable to reduce TNF- $\alpha$ and IL-1 $\beta$ in healthy humans [151]. On the other hand, zinc indicates anti-apoptotic effects at the thymic and peripheral level through enhancing the $\mathrm{Bcl}-2 / \mathrm{Bax}$ ratio and inhibiting caspases-3,-6, and -9 production [152].

Based on mentioned features, zinc is currently considered as a promising therapeutic candidate for COVID-19 infection [21]. It has been shown that $\mathrm{Zn}^{2+}$ cations coupled with zinc ionophores pyrithione have an inhibitory effect on replication and activity of coronavirus RNA polymerase (RNA dependent RNA polymerase, RdRp) [153]. It seems that one of the most common strategies for COVID-19 management is blocking virus entry into host cells through interaction with ACE2 [21]. In a study performed by Speth and coworkers, the notable effect of $100 \mathrm{mM}$ zinc was shown on the reduction of recombinant human ACE2 activity in rat lungs [154]. This concentration is nearby to physiological standards of zinc, however, the modulating effect of zinc on the interaction between ACE2 and SARS-CoV-2 seems to be only in the hypothetical stage $[155,156]$. Researches indicate that chloroquine as a zinc ionophore agent can rise $\mathrm{Zn}^{2+}$ flux into the cells $[157,158]$.

Based on recent studies, zinc in absence of chloroquine might indicate similar advantages without harmful side effects of chloroquine [158]. These results have been reported regarding the effects of zinc ionophores (quercetin and epigallocatechin-gallate) [159] with lower toxicity. However, there is an essential need to conduct clinical trials and evaluate this hypothesis [160]. The deficiency of zinc can lead to an imbalance and abnormal activity in the immune system. For instance, severe deficiency can result in high susceptibility to infections, weight loss, skin disorders, gastrointestinal disorders, and growth retardation [161]. Based on recently published data, zinc is capable to inhibit SAR-CoV RNA polymerase [162]. Thus, it has been

Table 2 Current clinical trials related to the combinational therapy with minerals in COVID-19 patients

\begin{tabular}{|c|c|c|c|c|c|}
\hline Minerals & NCT number & Study title & Phase & Age & Status* \\
\hline Selenium & NCT04877509 & $\begin{array}{l}\text { Micronutrient status involved in immunity in elderly patients with } \\
\text { COVID-19 (MicroCovAging) }\end{array}$ & NA & 50 years and older & Completed \\
\hline \multirow[t]{4}{*}{ Zinc } & NCT04370782 & $\begin{array}{l}\text { Hydroxychloroquine and zinc with either azithromycin or doxycy- } \\
\text { cline for treatment of COVID-19 in outpatient setting }\end{array}$ & 4 & 30 years and older & Completed \\
\hline & NCT04377646 & $\begin{array}{l}\text { A study of hydroxychloroquine and zinc in the prevention of } \\
\text { COVID-19 infection in military healthcare workers }\end{array}$ & 3 & $18-65$ years & Not yet recruiting \\
\hline & NCT04446104 & $\begin{array}{l}\text { A preventive treatment for migrant workers at high-risk of COVID- } \\
19\end{array}$ & 3 & $21-60$ years & Completed \\
\hline & NCT04447534 & $\begin{array}{l}\text { Zinc with chloroquine/hydroxychloroquine in treatment of COVID- } \\
19\end{array}$ & 3 & 18 years and older & Recruiting \\
\hline
\end{tabular}

*Please refer to http://clinicaltrials.gov for more details 
suggested that $\mathrm{Zn}^{2+}$ cations especially in complex with zinc ionophore pyrithione can inhibit RdRP and may be considered as potential therapeutic candidates against COVID-19. Zinc function is related to interaction with the zinc-binding domain (HEXXH motif) located on the ACE2 receptor as a zinc metallopeptidase [163]. At present, several ongoing clinical studies have been conducted regarding the zinc status in COVID-19 patients (Table 2 ).

\section{Vitamins and cytokine storm in COVID-19}

Similar to the SARS and MERS, different levels of cytokine storm have also been detected in a large number of patients with severe COVID-19, especially in ICU patients. The cytokine storm is considered one of the most important causes of death. Based on recent findings, vitamins alone or in combination with approved drugs can counteract both DNA and RNA viruses and seems to be a rationale for using these micronutrients in the management of COVID-19 [164]. It has been implicated that micronutrients and minerals may prevent cytokine storms by interfering with the production of different inflammatory cytokines (Fig. 4). Based on invitro study results, the DNA binding of NF- $\mathrm{kB}$ to promoters of interleukins (e.g., IL-6, IL-8, IL-12) and cyclooxygenase (COX2) can be down-regulated by $1 \alpha, 25$ dihydroxy vitamin D3 and led to reduced transcription of all these interleukins and COX-2. Besides, vitamin E may reduce NF- $\kappa \mathrm{B}$ binding activity into the DNA and down-regulate the production of a pro-inflammatory cytokine such as IL-6, IL-8, IL-12, and COX-2 [164], which are involved in severe forms of COVID19 infection [125].

It has been also reported that vitamin $\mathrm{C}$ can increase antiviral cytokines level (e.g., IFN- $\alpha / \beta$ ) and free radical formation, and subsequently decrease viral load. Besides, it can attenuate the excessive inflammatory responses and hyperactivation of immune cells [125]. Vitamin C as an important micronutrient can protect some vital cells and micro-organelles against ROS-mediated injury and oxidative-mediated damage. Although, further clinical trials are needed to confirm the effects of vitamin C on COVID-19. At present, a clinical trial (phase II) in Zhongnan Hospital of Wuhan University in China is under evaluation of vitamin $\mathrm{C}$ effects and its intervention with cytokine storms and the risk of acute respiratory distress syndrome in COVID-19 patients (https://clinicaltrials.gov/ct2/show/NCT04264533). Besides, the succinate form of vitamin D and vitamin E (as a functional form), can suppress ROS and prevent activation of a wide series of genes and modification of enzymatic pathways in the cytoplasm.

In summary, the nucleocapsid and/or spike proteins of the SARS-coronavirus may cause the induction of the synthesis of the pro-inflammatory cytokine directly through binding to the promoters of the specific DNA motifs such as NF- $\mathrm{KB}$ and CCAAT/enhancer-binding protein (C/EBP). Besides, viral agents may activate NF- $\kappa \mathrm{B}$ by interaction with its specific

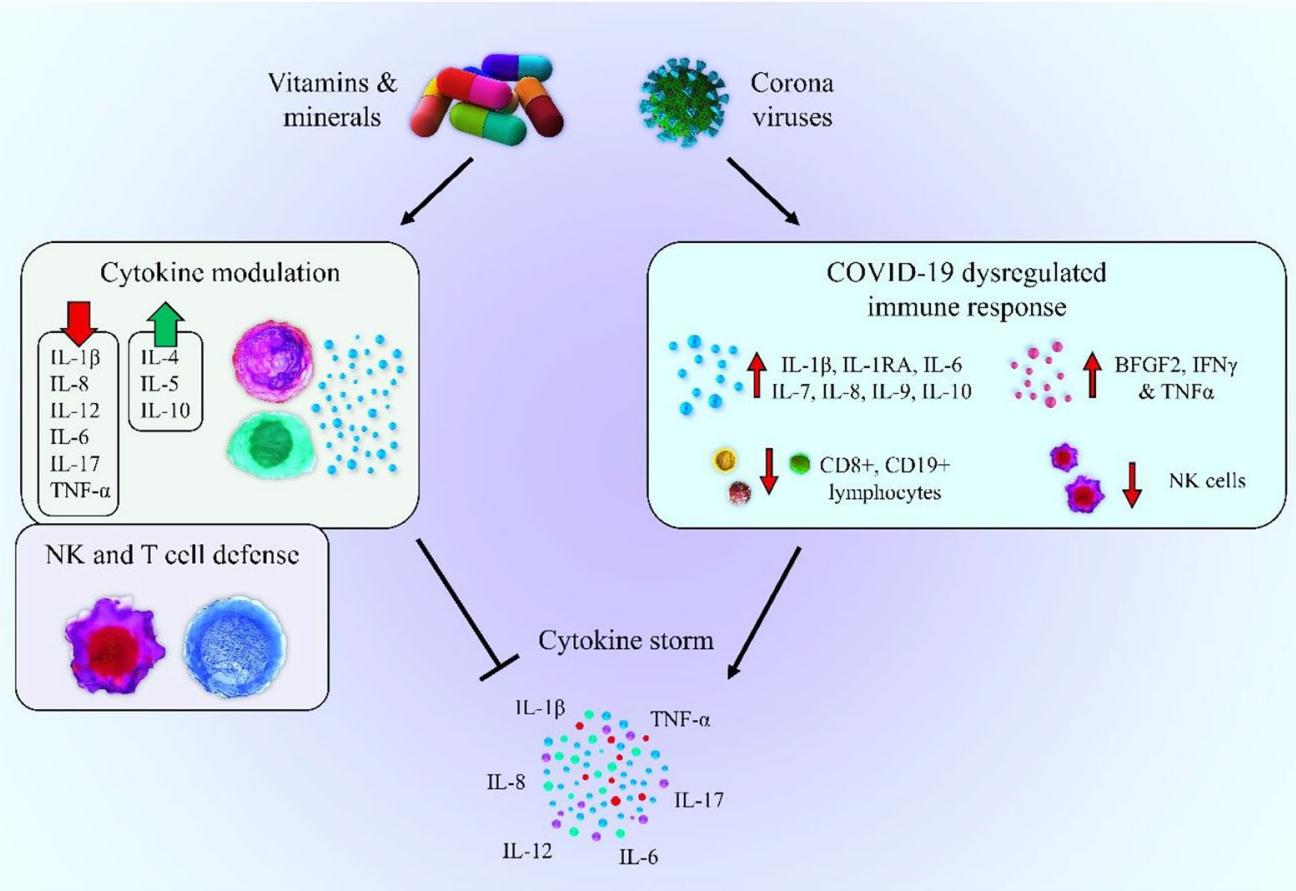

Fig. 4 A potential role of vitamins and minerals in the prevention of cytokine storm during COVID-19 infection 
subdomains. Therefore, viral proteins may increase (directly or indirectly) the production of IL-1, IL-6, IL-8, IL-17, and $\mathrm{TNF}-\alpha$ during the development of COVID-19 infection. In this regard, vitamins such as A, D, and E may decrease the binding of NF- $\mathrm{KB}$ to their specific sequences on DNA and reduce the synthesis of the pro-inflammatory cytokine, prevent or decrease the cytokine storms [164]. The welldesigned trials are needed to clarify the role of the vitamin in COVID-19 patients, alone or in combination with different approved drugs.

\section{Final remarks and conclusions}

Despite the relentless efforts of scientists, researchers, and medicians towards the COVID-19 infection, the adequate treatment of disease manifestations remains an outstanding challenge. Currently, it has been revealed that the nutritional aspects of COVID-19 patients could play an important role in the management of the disease process. In this regard, micronutrients including different vitamins and minerals are considered the most effective agents against infectious diseases due to their anti-inflammatory and antioxidant properties. It is noteworthy that an inadequate level of vitamins and minerals seriously disrupt the function of the immune system against pathogens. In contrast, a sufficient level of micronutrients may beneficially affect the accuracy of immune functionality, modulate chronic inflammatory and autoimmune conditions, and reduce the risk and severity of the infection. Besides, the immune system undergoes several changes during different stages of life and may present lower protecting features in older people, thus, an adequate supply of micronutrients plays a key role in improving the immunity function.

At present, the lack of specific therapeutic options has been led to symptomatic management of COVID-19 patients with severe infection through oxygen therapy and mechanical ventilation. Regarding the range of favorable effects of the vitamins including safety, ease of use, as well as direct effects on immune cell activity, pulmonary ACE2 expression, and reduction of surface tension, the clinical applications of them as adjuvant therapies can be considered for COVID-19 patients. However, we need a better understanding of the micronutrient status in COVID-19 patients especially regarding vitamins with a narrow therapeutic range.

Acknowledgements The authors would like to acknowledge the Infectious and Tropical Diseases Research Center at Tabriz University of Medical Sciences.

Author contribution $\mathrm{FL}, \mathrm{ZL}, \mathrm{HZ}$, and $\mathrm{AB}$ gathered the data and drafted the manuscript. LR, MAK, and AS helped in the interpretation of the data. $\mathrm{LR}, \mathrm{AS}, \mathrm{BB}$, and $\mathrm{BN}$ conceived and revised the context and finalized the manuscript. All authors have read the journal's authorship statement and approved the submission of the manuscript.

Funding The authors received no financial support for this research.

\section{Declarations}

Conflict of interest All authors have read the journal's policy and declared no conflict of interests.

\section{References}

1. Kulcsar MA, et al. High risk of COVID-19 infection for head and neck surgeons. Int Arch Otorhinolaryngol. 2020;24:e129-30.

2. Shanmugaraj B, et al. Perspectives on monoclonal antibody therapy as potential therapeutic intervention for Coronavirus disease-19 (COVID-19). Asian Pac J Allergy Immunol. 2020;38:10-8.

3. Chang R, Sun WZ. Repositioning chloroquine as antiviral prophylaxis against COVID-19: potential and challenges. Drug Discov Today. 2020;25:1786-92.

4. Pourseif MM, et al. A domain-based vaccine construct against SARS-CoV-2, the causative agent of COVID-19 pandemic: development of self-amplifying mRNA and peptide vaccines. Bioimpacts. 2021;11:65-84.

5. Rahbarnia L, et al. Isolation and characterization of a novel human $\mathrm{scFv}$ inhibiting EGFR vIII expressing cancers. Immunol Lett. 2016;180:31-8.

6. Khiavi MA, Safary A, Somi MH. Recent advances in targeted therapy of colorectal cancer: impacts of monoclonal antibodies nanoconjugates. BioImpacts. 2019;9:123.

7. Farajnia $S$, et al. Molecular cloning and characterization of P4 nuclease from Leishmania infantum. Enzyme Res. 2011;2011:1-6.

8. Montazer-Saheb S, et al. Seroprevalence of Helicobacter pylori infection in patients suffering from gastric symptoms in the Northwest of Iran. Afr J Microbiol Res. 2011;5:3616-9.

9. Maggini S, Pierre A, Calder PC. Immune function and micronutrient requirements change over the life course. Nutrients. 2018;10:1531.

10. Haryanto B, et al. Multivitamin supplementation supports immune function and ameliorates conditions triggered by reduced air quality. Vitam Miner. 2015;4:1-15.

11. Godoy-Parejo C, et al. Roles of vitamins in stem cells. Cell Mol Life Sci. 2020;77:1771-91.

12. Brugliera L, et al. Nutritional management of COVID-19 patients in a rehabilitation unit. Eur J Clin Nutr. 2020;74:860-3.

13. Velavan TP, Meyer CG. The COVID-19 epidemic. Tropical Med Int Health. 2020;25:278.

14. Schoeman D, Fielding BC. Coronavirus envelope protein: current knowledge. Virol J. 2019;16:69.

15. Rehman ZU, et al. Supplementation of vitamin e protects chickens from Newcastle disease virus-mediated exacerbation of intestinal oxidative stress and tissue damage. Cell Physiol Biochem. 2018;47:1655-66.

16. Mustafa S, Balkhy H, Gabere MN. Current treatment options and the role of peptides as potential therapeutic components for Middle East Respiratory Syndrome (MERS): a review. J Infect Public Health. 2018;11:9-17.

17. Chen N, et al. Epidemiological and clinical characteristics of 99 cases of 2019 novel coronavirus pneumonia in Wuhan, China: a descriptive study. Lancet. 2020;395:507-13. 
18. de Souza $\mathrm{TH}$, et al. Clinical manifestations of children with COVID-19: a systematic review. Pediatr Pulmonol. 2020;55:1892-9.

19. de Amorim Santos J, et al. Oral manifestations in patients with COVID-19: a living systematic review. J Dent Res. 2021;100:141-54.

20. da Rosa Mesquita R, et al. Clinical manifestations of COVID-19 in the general population: systematic review. Wien Klin Wochenschr. 2020;133:377-82.

21. Bai Y, et al. Presumed asymptomatic carrier transmission of COVID-19. J Am Med Assoc. 2020;323:1406-7.

22. Chen $X$, et al. Human monoclonal antibodies block the binding of SARS-CoV-2 spike protein to angiotensin converting enzyme 2 receptor. Cell Mol Immunol. 2020;17:647-9.

23. Chan JF-W, et al. A familial cluster of pneumonia associated with the 2019 novel coronavirus indicating person-to-person transmission: a study of a family cluster. Lancet. 2020;395:514-23.

24. Guan W-J, et al. Clinical characteristics of coronavirus disease 2019 in China. N Engl J Med. 2020;382:1708-20.

25. Keski H. Hematological and inflammatory parameters to predict the prognosis in COVID-19. Indian J Hematol Blood Transfus. 2021;1-9.

26. Docherty AB, et al. Features of 20133 UK patients in hospital with covid-19 using the ISARIC WHO Clinical Characterisation Protocol: prospective observational cohort study. BMJ. 2020;369:1-12.

27. Huang C, et al. Clinical features of patients infected with 2019 novel coronavirus in Wuhan, China. Lancet. 2020;395:497-506.

28. Wu Z, McGoogan JM. Characteristics of and important lessons from the coronavirus disease 2019 (COVID-19) outbreak in China: summary of a report of 72314 cases from the Chinese Center for Disease Control and Prevention. JAMA. 2020;323:1239-42.

29. Hasan SS, et al. Mortality in COVID-19 patients with acute respiratory distress syndrome and corticosteroids use: a systematic review and meta-analysis. Expert Rev Respir Med. 2020;14:1149-63.

30. Richardson S, et al. Presenting characteristics, comorbidities, and outcomes among 5700 patients hospitalized with COVID-19 in the New York City area. JAMA. 2020;323:2052-9.

31. Li J, et al. Epidemiology of COVID-19: a systematic review and meta-analysis of clinical characteristics, risk factors, and outcomes. J Med Virol. 2021;93:1449-58.

32. $\mathrm{Zu} \mathrm{ZY}$, et al. Coronavirus disease 2019 (COVID-19): a perspective from China. Radiology. 2020; 296(2):15-25.

33. Banerjee A, et al. Bats and coronaviruses. Viruses. 2019;11:41.

34. Keil SD, Bowen R, Marschner S. Inactivation of M iddle E ast respiratory syndrome coronavirus (MERS-C o V) in plasma products using a riboflavin-based and ultraviolet light-based photochemical treatment. Transfusion. 2016;56:2948-52.

35. Kruse RL. Therapeutic strategies in an outbreak scenario to treat the novel coronavirus originating in Wuhan, China. F1000Res. 2020;9:72.

36. Chan JF, et al. Middle East respiratory syndrome coronavirus: another zoonotic betacoronavirus causing SARS-like disease. Clin Microbiol Rev. 2015;28:465-522.

37. De Wit E, et al. SARS and MERS: recent insights into emerging coronaviruses. Nat Rev Microbiol. 2016;14:523.

38. Glowacka I, et al. Evidence that TMPRSS2 activates the severe acute respiratory syndrome coronavirus spike protein for membrane fusion and reduces viral control by the humoral immune response. J Virol. 2011;85:4122-34.

39. Dimitrov DS. The secret life of ACE2 as a receptor for the SARS virus. Cell. 2003;115:652-3.

40. Perlman S, Netland J. Coronaviruses post-SARS: update on replication and pathogenesis. Nat Rev Microbiol. 2009;7:439-50.
41. Yeung KS, Yamanaka GA, Meanwell NA. Severe acute respiratory syndrome coronavirus entry into host cells: opportunities for therapeutic intervention. Med Res Rev. 2006;26:414-33.

42. Sun Y, et al. Host cytokine storm is associated with disease severity of severe fever with thrombocytopenia syndrome. J Infect Dis. 2012;206:1085-94.

43. Gobeil F Jr, Sirois P, Regoli D. Preclinical pharmacology, metabolic stability, pharmacokinetics and toxicology of the peptidic kinin B1 receptor antagonist R-954. Peptides. 2014;52:82-9.

44. Callaway E, Ledford H. How to redesign COVID vaccines so they protect against variants. Nature. 2021;590:15-6.

45. Tsitsilonis OE, et al. SARS-CoV-2 infection is asymptomatic in nearly half of adults with robust anti-spike protein receptorbinding domain antibody response. Vaccines. 2021;9:207.

46. Dai L, Gao GF. Viral targets for vaccines against COVID-19. Nat Rev Immunol. 2021;21:73-82.

47. Salvatori G, et al. SARS-CoV-2 SPIKE PROTEIN: an optimal immunological target for vaccines. J Transl Med. 2020;18:222.

48. Patel S, Saxena B, Mehta P. Recent updates in the clinical trials of therapeutic monoclonal antibodies targeting cytokine storm for the management of COVID-19. Heliyon. 2021;7(2):e06158.

49. Anand T, et al. Phage display technique as a tool for diagnosis and antibody selection for coronaviruses. Curr Microbiol. 2021;78:1124-34.

50. Wang R, et al. The vitamin D for COVID-19 (VIVID) trial: a pragmatic cluster-randomized design. Contemp Clin Trials. 2021;100:106176.

51. Gombart AF, Pierre A, Maggini S. A review of micronutrients and the immune System-Working in harmony to reduce the risk of infection. Nutrients. 2020;12:236.

52. Maggini S, et al. Feeding the immune system: the role of micronutrients in restoring resistance to infections. CAB Rev. 2008;3:1-21.

53. Ooi JH, et al. Vitamin D regulates the gut microbiome and protects mice from dextran sodium sulfate-induced colitis. J Nutr. 2013;143:1679-86.

54. Cantorna MT, et al. Vitamin D, immune regulation, the microbiota, and inflammatory bowel disease. Exp Biol Med. 2014;239:1524-30.

55. Biesalski HK. Nutrition meets the microbiome: micronutrients and the microbiota. Ann N Y Acad Sci. 2016;1372:53-64.

56. Yoshii K, et al. Metabolism of dietary and microbial vitamin B family in the regulation of host immunity. Front Nutr. 2019;6:48.

57. Cantorna MT, Snyder L, Arora J. Vitamin A and vitamin D regulate the microbial complexity, barrier function, and the mucosal immune responses to ensure intestinal homeostasis. Crit Rev Biochem Mol Biol. 2019;54:184-92.

58. Lee H, Ko G. Antiviral effect of vitamin A on norovirus infection via modulation of the gut microbiome. Sci Rep. 2016;6:1-9.

59. Wu H-J, Wu E. The role of gut microbiota in immune homeostasis and autoimmunity. Gut microbes. 2012;3:4-14.

60. Owaga E, et al. Th17 cells as potential probiotic therapeutic targets in inflammatory bowel diseases. Int J Mol Sci. 2015; 16:20841-58.

61. Francino MP. Early development of the gut microbiota and immune health. Pathogens. 2014;3:769-90.

62. Wishart K. Increased micronutrient requirements during physiologically demanding situations: review of the current evidence. Vitam Miner. 2017;6:1-16.

63. Lin Z, Li W. The roles of vitamin D and its analogs in inflammatory diseases. Curr Top Med Chem. 2016;16:1242-61.

64. Topilski I, et al. The anti-inflammatory effects of 1, 25-dihydroxyvitamin D3 on Th2 cells in vivo are due in part to the control of integrin-mediated T lymphocyte homing. Eur J Immunol. 2004;34:1068-76. 
65. Carr AC, Maggini S. Vitamin C and immune function. Nutrients. 2017;9:1211.

66. Sakakeeny L, et al. Plasma pyridoxal-5-phosphate is inversely associated with systemic markers of inflammation in a population of US adults. J Nutr. 2012;142:1280-5.

67. Boretti A, Banik BK. Intravenous vitamin $\mathrm{C}$ for reduction of cytokines storm in acute respiratory distress syndrome. PharmaNutr. 2020;12:100190.

68. Gariballa S. Vitamin and mineral supplements for preventing infections in older people. BMJ. 2005;331:304-5.

69. Galanakis CM. The food systems in the era of the coronavirus (COVID-19) pandemic crisis. Foods. 2020;9:523.

70. Thirumdas R, et al. Role of food nutrients and supplementation in fighting against viral infections and boosting immunity: a review. Trends Food Sci Technol. 2021;110:1124-34.

71. Mora JR, Iwata M, von Andrian UH. Vitamin effects on the immune system: vitamins A and D take centre stage. Nat Rev Immunol. 2008;8:685-98.

72. Dennert G, Lotan R. Effects of retinoic acid on the immune system: stimulation of T killer cell induction. Eur J Immunol. 1978;8:23-9.

73. Ertesvag A, et al. Retinoic acid stimulates the cell cycle machinery in normal $\mathrm{T}$ cells: involvement of retinoic acid receptormediated IL-2 secretion. J Immunol. 2002;169:5555-63.

74. Carman JA, Smith SM, Hayes CE. Characterization of a helper $\mathrm{T}$ lymphocyte defect in vitamin A-deficient mice. J Immunol. 1989;142:388-93.

75. Raverdeau M, Mills KH. Modulation of T cell and innate immune responses by retinoic acid. J Immunol. 2014;192:2953-8.

76. Ross AC, Stephensen CB. Vitamin A and retinoids in antiviral responses. FASEB J. 1996;10:979-85.

77. Caccialanza R, et al. Early nutritional supplementation in noncritically ill patients hospitalized for the 2019 novel coronavirus disease (COVID-19): rationale and feasibility of a shared pragmatic protocol. Nutrition. 2020;74:110835.

78. Hashimoto $\mathrm{S}$, et al. Retinoic acid differentially regulates interleukin-1beta and interleukin-1 receptor antagonist production by human alveolar macrophages. Leuk Res. 1998;22:1057-61.

79. Timoneda J, et al. Vitamin A deficiency and the lung. Nutrients. 2018;10:1132.

80. Trottier C, et al. Retinoids inhibit measles virus through a type I IFN-dependent bystander effect. FASEB J. 2009;23:3203-12.

81. Angulo A, et al. Ligand induction of retinoic acid receptors alters an acute infection by murine cytomegalovirus. J Virol. 1998;72:4589-600.

82. Trottier $\mathrm{C}$, et al. Retinoids inhibit measles virus in vitro via nuclear retinoid receptor signaling pathways. Antiviral Res. 2008;80:45-53.

83. Guillin OM, et al. Selenium, selenoproteins and viral infection. Nutrients. 2019;11:2101.

84. Bai Y, et al. Presumed asymptomatic carrier transmission of COVID-19. JAMA. 2020;323:1406-7.

85. Ragan I, et al. Pathogen reduction of SARS-CoV-2 virus in plasma and whole blood using riboflavin and UV light. PLoS ONE. 2020;15:e0233947.

86. Frieman M, et al. Severe acute respiratory syndrome coronavirus ORF6 antagonizes STAT1 function by sequestering nuclear import factors on the rough endoplasmic reticulum/Golgi membrane. J Virol. 2007;81:9812-24.

87. Spiegel M, et al. Inhibition of Beta interferon induction by severe acute respiratory syndrome coronavirus suggests a two-step model for activation of interferon regulatory factor 3. J Virol. 2005;79:2079-86.

88. Vrolijk MF, et al. The vitamin B6 paradox: supplementation with high concentrations of pyridoxine leads to decreased vitamin B6 function. Toxicol In Vitro. 2017;44:206-12.
89. Özdemir ZÖ, Şentürk M, Ekinci D. Inhibition of mammalian carbonic anhydrase isoforms I, II and VI with thiamine and thiamine-like molecules. J Enzyme Inhib Med Chem. 2013;28:316-9.

90. Shakoor H, et al. Be well: a potential role for vitamin B in COVID-19. Maturitas. 2020;144:108-11.

91. Powers HJ. Riboflavin (vitamin B-2) and health. Am J Clin Nutr. 2003;77:1352-60.

92. Jones HD, et al. Nicotinamide exacerbates hypoxemia in ventilator-induced lung injury independent of neutrophil infiltration. PLoS ONE. 2015;10:e0123460.

93. Mikkelsen K, et al. The effects of vitamin B on the immune/ cytokine network and their involvement in depression. Maturitas. 2017;96:58-71.

94. Liu B, et al. Can we use interleukin-6 (IL-6) blockade for coronavirus disease 2019 (COVID-19)-induced cytokine release syndrome (CRS)? J Autoimmun. 2020;111:102452.

95. Mikkelsen K, Apostolopoulos V. Vitamin B1, B2, B3, B5, and B6 and the immune system. In: Nutrition and immunity. Springer; 2019. p. 115-25.

96. Michele CA, et al. Vitamin supplements in the Era of SARSCov2 pandemic. GSC Biol Pharm Sci. 2020;11:007-19.

97. Patel JJ, Martindale RG, McClave SA. Relevant nutrition therapy in COVID-19 and the constraints on its delivery by a unique disease process. Nutr Clin Pract. 2020;35:792-9.

98. Ellsworth MA, et al. Acute liver failure secondary to niacin toxicity. Case Rep Pediatr. 2014;2014:1-3.

99. Traber MG, Stevens JF. Vitamins C and E: beneficial effects from a mechanistic perspective. Free Radical Biol Med. 2011;51:1000-13.

100. Chuangchot $\mathrm{N}$, et al. Oral vitamin $\mathrm{C}$ treatment increases polymorphonuclear cell functions in type 2 diabetes mellitus patients with poor glycemic control. Nutr Res. 2020;79:50-9.

101. Hager DN, et al. The Vitamin C, Thiamine and Steroids in Sepsis (VICTAS) Protocol: a prospective, multi-center, doubleblind, adaptive sample size, randomized, placebo-controlled, clinical trial. Trials. 2019;20:197.

102. Litwak JJ, et al. Vitamin C, hydrocortisone, and thiamine for the treatment of severe sepsis and septic shock: a retrospective analysis of real-world application. J Clin Med. 2019;8:478.

103. Kim SB, Yeom JS. Reply: vitamin C as a possible therapy for COVID-19. Infect Chemother. 2020;52(2):224-5.

104. Verrax J, Calderon PB. The controversial place of vitamin C in cancer treatment. Biochem Pharmacol. 2008;76:1644-52.

105. Rees D, Kelsey H, Richards J. Acute haemolysis induced by high dose ascorbic acid in glucose-6-phosphate dehydrogenase deficiency. BMJ. 1993;306:841.

106. Panarese A, Shahini E. Covid-19, and vitamin D. Aliment Pharmacol Ther. 2020;51(10):993-5.

107. Panfili F, et al. Possible role of vitamin D in Covid-19 infection in pediatric population. J Endocrinol Investig. 2020;44:1-9.

108. Conti $\mathrm{P}$, et al. Induction of pro-inflammatory cytokines (IL-1 and IL-6) and lung inflammation by Coronavirus-19 (COVI-19 or SARS-CoV-2): anti-inflammatory strategies. J Biol Regul Homeost Agents. 2020;34:1.

109. Teymoori-Rad M, et al. The interplay between vitamin D and viral infections. Rev Med Virol. 2019;29:e2032.

110. Hirsch D, et al. Decreased anti-inflammatory responses to vitamin D in neonatal neutrophils. Mediat Inflamm. 2011;2011:598345.

111. Yip KH, et al. Mechanisms of vitamin $\mathrm{D}_{3}$ metabolite repression of IgE-dependent mast cell activation. J Allergy Clin Immunol. 2014;133(5):1356-64.

112. Schett G, Sticherling M, Neurath MF. COVID-19: risk for cytokine targeting in chronic inflammatory diseases? Nat Rev Immunol. 2020;20:271-2. 
113. Tabatabaeizadeh SA, et al. High Dose Supplementation of Vitamin D Affects Measures of Systemic Inflammation: Reductions in High Sensitivity C-Reactive Protein Level and Neutrophil to Lymphocyte Ratio (NLR) Distribution. J Cell Biochem. 2017;118:4317-22.

114. Karkeni E, et al. Vitamin D controls tumor growth and CD8+ T cell infiltration in breast cancer. Front Immunol. 2019;10:1307.

115. Zdrenghea MT, et al. Vitamin D modulation of innate immune responses to respiratory viral infections. Rev Med Virol. 2017;27:e1909.

116. Ebadi M, Montano-Loza AJ. Perspective: improving vitamin D status in the management of COVID-19. Eur J Clin Nutr. 2020;74:856-9.

117. Chen $Y$, et al. Vitamin D receptor inhibits nuclear factor $\kappa B$ activation by interacting with IкB kinase $\beta$ protein. J Biol Chem. 2013;288:19450-8.

118. Jeffery LE, et al. 1,25-Dihydroxyvitamin D3 and IL-2 combine to inhibit $\mathrm{T}$ cell production of inflammatory cytokines and promote development of regulatory T cells expressing CTLA-4 and FoxP3. J Immunol. 2009; 183:5458-67.

119. Wimalawansa SJ. Vitamin D deficiency: effects on oxidative stress, epigenetics, gene regulation, and aging. Biology (Basel). 2019;8(2):30

120. Monlezun DJ, et al. Vitamin D status and acute respiratory infection: cross sectional results from the United States National Health and Nutrition Examination Survey, 2001-2006. Nutrients. 2015;7:1933-44.

121. Abu-Mouch S, et al. Vitamin D supplementation improves sustained virologic response in chronic hepatitis C (genotype 1)-naïve patients. World J Gastroenterol. 2011;17:5184-90.

122. Mrityunjaya $\mathbf{M}$, et al. Immune-boosting, antioxidant and antiinflammatory food supplements targeting pathogenesis of COVID-19. Front Immunol. 2020;11:570122.

123. Ginde AA, et al. High-dose monthly vitamin D for prevention of acute respiratory infection in older long-term care residents: a randomized clinical trial. J Am Geriatr Soc. 2017;65:496-503.

124. Cao X. COVID-19: immunopathology and its implications for therapy. Nat Rev Immunol. 2020;20:269-70.

125. Im JH, et al. Nutritional status of patients with COVID-19. Int J Infect Dis. 2020;100:390-3.

126. Xu J, et al. Vitamin D alleviates lipopolysaccharide-induced acute lung injury via regulation of the renin-angiotensin system. Mol Med Rep. 2017;16:7432-8.

127. Teymoori-Rad M, Marashi SM. Vitamin D and Covid-19: from potential therapeutic effects to unanswered questions. Rev Med Virol. 2020;31(2):e2159.

128. Jia HP, et al. ACE2 receptor expression and severe acute respiratory syndrome coronavirus infection depend on differentiation of human airway epithelia. J Virol. 2005;79:14614-21.

129. Kieliszek M, Lipinski B. Selenium supplementation in the prevention of coronavirus infections (COVID-19). Med Hypotheses. 2020;143:109878.

130. Shakoor $\mathrm{H}$, et al. Immune-boosting role of vitamins $\mathrm{D}, \mathrm{C}, \mathrm{E}$, zinc, selenium and omega-3 fatty acids: could they help against COVID-19? Maturitas. 2021;143:1-9.

131. Liu M, et al. Mixed tocopherols have a stronger inhibitory effect on lipid peroxidation than $\alpha$-tocopherol alone. J Cardiovasc Pharmacol. 2002;39:714-21

132. Will Taylor E, et al. Cellular selenoprotein mRNA tethering via antisense interactions with Ebola and HIV-1 mRNAs may impact host selenium biochemistry. Curr Top Med Chem. 2016;16:1530-5.

133. Steinbrenner H, et al. Dietary selenium in adjuvant therapy of viral and bacterial infections. Adv Nutr. 2015;6:73-82.

134. Rayman MP. Selenium and human health. Lancet. 2012;379:1256-68.
135. Baum MK, et al. High risk of HIV-related mortality is associated with selenium deficiency. J Acquir Immune Defic Syndr Hum Retrovirol. 1997;15(5):370-4

136. Hou J-C. Inhibitory effect of selenite and other antioxidants on complement-mediated tissue injury in patients with epidemic hemorrhagic fever. Biol Trace Elem Res. 1997;56:125-30.

137. Hoffmann PR, Berry MJ. The influence of selenium on immune responses. Mol Nutr Food Res. 2008;52:1273-80.

138. Beck MA, Handy J, Levander OA. Host nutritional status: the neglected virulence factor. Trends Microbiol. 2004;12:417-23.

139. Tomo S, et al. Selenium to selenoproteins-role in COVID-19. EXCLI J. 2021;20:781

140. Moghaddam A, et al. Selenium deficiency is associated with mortality risk from COVID-19. Nutrients. 2020;12:2098.

141. Cheng Y, et al. Kidney disease is associated with inhospital death of patients with COVID-19. Kidney Int 2020;97(5):829-38.

142. Zhang $\mathrm{H}$, et al. Angiotensin-converting enzyme 2 (ACE2) as a SARS-CoV-2 receptor: molecular mechanisms and potential therapeutic target. Intensive Care Med. 2020;46:586-90.

143. Zhang J, et al. Association between regional selenium status and reported outcome of COVID-19 cases in China. Am J Clin Nutr. 2020;111:1297-9.

144. Zhang L, Liu Y. Potential interventions for novel coronavirus in China: a systematic review. J Med Virol. 2020;92:479-90.

145. Zheng Y-Y, et al. COVID-19 and the cardiovascular system. Nat Rev Cardiol. 2020;17:259-60.

146. Zheng Y-Y, et al. Reply to: 'Interaction between RAAS inhibitors and ACE2 in the context of COVID-19.' Nat Rev Cardiol. 2020;17:313-4.

147. Zhou P, et al. A pneumonia outbreak associated with a new coronavirus of probable bat origin. Nature. 2020;579:270-3.

148. Kumar A, et al. Potential role of zinc supplementation in prophylaxis and treatment of COVID-19. Med Hypotheses. 2020;144:109848

149. Ibs K-H, Rink L. Zinc-altered immune function. J Nutr. 2003;133(5):1452S-6S.

150. Pasternak C. A novel form of host defence: membrane protection by $\mathrm{Ca} 2+$ and Zn2+. Biosci Rep. 1987;7:81-91.

151. Cakman I, Kirchner H, Rink L. Zinc supplementation reconstitutes the production of interferon- $\alpha$ by leukocytes from elderly persons. J Interferon Cytokine Res. 1997;17:469-72.

152. Perry DK, et al. Zinc is a potent inhibitor of the apoptotic protease, caspase-3 a novel target for zinc in the inhibition of apoptosis. J Biol Chem. 1997;272:18530-3.

153. Te Velthuis AJ, et al. Zn2+ inhibits coronavirus and arterivirus RNA polymerase activity in vitro and zinc ionophores block the replication of these viruses in cell culture. PLoS Pathog. 2010;6:e1001176.

154. Speth R, et al. Concentration-dependent effects of zinc on angiotensin-converting enzyme-2 activity (1067.4). FASEB J. 2014;28:1067.4

155. Chilvers M, et al. The effects of coronavirus on human nasal ciliated respiratory epithelium. Eur Respir J. 2001;18:965-70.

156. Gritsenko VA, et al. Zinc, respiratory tract infections and COVID-19-July 2020. Int J Mol Med. 2020;46:17-26.

157. Xue J, et al. Chloroquine is a zinc ionophore. PLoS ONE. 2014;9:e109180.

158. Guastalegname M, Vallone A. Could chloroquine/hydroxychloroquine be harmful in coronavirus disease 2019 (COVID-19) treatment? Clin Infect Dis. 2020;71(15):888-9.

159. Dabbagh-Bazarbachi $\mathrm{H}$, et al. Zinc ionophore activity of quercetin and epigallocatechin-gallate: from Hepa 1-6 cells to a liposome model. J Agric Food Chem. 2014;62:8085-93.

160. Skalny AV, et al. Zinc and respiratory tract infections: perspectives for COVID-19. Int J Mol Med. 2020;46:17-26. 
161. Prasad AS. Clinical manifestations of zinc deficiency. Annu Rev Nutr. 1985;5:341-63.

162. Khan A, et al. Phylogenetic analysis and structural perspectives of RNA-dependent RNA-polymerase inhibition from SARsCoV-2 with natural products. Interdiscip Sci. 2020;12:335-48.

163. Acharya KR, et al. Ace revisited: a new target for structure-based drug design. Nat Rev Drug Discov. 2003;2:891-902.
164. Fiorino S, et al. Cytokine storm in aged people with CoV-2: possible role of vitamins as therapy or preventive strategy. Aging Clin Exp Res. 2020;32:2115-31.

165. Cyprian F, et al. Immunomodulatory effects of vitamin D in pregnancy and beyond. Front Immunol. 2019;10:2739. 